\title{
RELATO E EXPERIÊNCIA DE ENSINO REMOTO EM UMA DISCIPLINA DE PRIMEIRO SEMESTRE NO CURSO DE ENGENHARIA QUÍMICA DA PUCRS
}

Claudio Luis Crescente Frankenberg - claudio@pucrs.br

PUCRS-Escola Politécnica - Engenharia Química

Avenida Ipiranga 6681 - prédio 30

90690-110 - Porto Alegre - RS

Resumo: É apresentado nesse trabalho um estado da arte sobre a transferência do modelo presencial para o modelo remoto em uma disciplina de primeiro nível do curso de Engenharia Química, a partir de uma descrição comparativa dos dois modelos em diferentes atividades. De forma geral evidencia-se a implementação e operação do Ensino Síncrono Remoto para realização de atividades de formação acadêmica em uma disciplina cujo objetivo principal é geral o sentido de pertencimento dos alunos ao curso e a Universidade. Com isto este estudo aborda a inserção da experimentação remota na prática do ensino em cursos superiores de engenharia com objetivo de compreender as complexidades pedagógicas deste tipo metodologia. O modelo remoto utilizado trabalhou com plataformas como o Moodle e o Zoom. Através disto, os acadêmicos demonstraram no final da disciplina uma boa receptibilidade e se sentiram seguros em relação ao processo em que enfrentamos neste semestre (2020/1). Em suma o processo remoto, no geral, foi visto como um recurso positivo no processo de ensino e aprendizagem para estudantes do ensino superior de engenharia química, no entanto, alguns pontos apresentaram necessidade de melhorias, como infraestrutura.

Palavras-chave: Ensino Remoto. Coronavirus. Calouros.

\section{INTRODUÇÃo}

O primeiro semestre de 2020, foi regado por desafios e descobertas. Após iniciativas isoladas no Estado do Rio Grande do Sul, a suspensão de aulas para tentar conter a pandemia de coronavírus se disseminou por toda a rede de ensino. Escolas municipais, estaduais, privadas e universidades cancelaram as atividades, levando à inédita paralisação do sistema de ensino no Rio Grande do Sul.

Diversos decretos estabeleceram orientações e restrições de atividades como forma de prevenir a contaminação durantes os meses de março e julho. O Governo Federal também foi protagonista na geração de portarias, principalmente vinculadas ao Ministério da Educação.

Com as novas regulamentações intensas mudanças na forma de conduzir a educação esperada e contratada foram necessárias. Este novo momento pode ser sintetizado por Pimentel (2020), quando este afirma que:

Para mantermos as aulas em andamento mesmo com as escolas $e$ universidades fechadas, o MEC apontou um caminho (ao menos para as instituições federais de ensino superior): "Autorizar, em caráter excepcional, a substituição das disciplinas presenciais, em andamento, por aulas que utilizem meios e tecnologias de informação e comunicação" (BRASIL, 2020). 
Essa portaria criou a oportunidade para considerarmos algumas alternativas de ensino-aprendizagem mediadas pelas tecnologias digitais em rede: Educação a Distância (EAD), Educação Online (EOL), Ensino Doméstico (homeschooling), Atividade Escolar Remota e Ensino Híbrido, entre outras possibilidades.

A substituição de aulas presenciais pela modalidade remota, autorizada pelo MEC enquanto perdura a pandemia do coronavírus, tem sido a opção da maioria das escolas e IES brasileiras, bem como na nossa IES. A Universidade não parou. Fomos pegos de surpresa, e gradativamente, através de capacitações, oficinas, e apoio dos colegas e principalmente do Núcleo de Inovação Pedagógica da Escola, desenvolvemos estratégias e nos motivamos para enfrentar este período.

Este artigo destaca o que aconteceu na disciplina de Introdução à Engenharia Química, visto ser esta é uma disciplina de primeiro semestre, onde além de todas as mudanças do sistema presencial para um presencial remoto apresentou uma gama de desafios críticos especialmente no que diz respeito a desenvolver um sentido de pertencimento ao curso, bem como de acolhimento dos calouros. Desta forma, iremos descrever algumas das atividades desenvolvidas, analisando como estas ocorriam através de uma metodologia presencial e como elas foram adaptadas para o processo remoto.

\section{DISCIPLINA DE INTRODUÇÃO À ENGENHARIA QUÍMICA}

\subsection{Características da disciplina}

A disciplina de Introdução à Engenharia Química do Curso de Engenharia Química da PUCRS foi implementada em 1989 (FRANKENBERG, 1996), e tem como objetivo capacitar o aluno na compreensão da profissão de Engenharia Química bem como de suas atividades profissionais. Além disto a disciplina busca fazer com que o discente conheça a Universidade, a Escola Politécnica e consequentemente, o Curso de Engenharia Química. Para isto preparase o aluno ao desenvolvimento do seu curso (currículo, disciplinas, códigos...), fazendo com que ele crie um espírito crítico e de análise no que se refere ao seu papel na Universidade e no curso de Engenharia Química.

Muitos trabalhos já foram apresentados a respeito desta disciplina, e/ou como ela se enquadra no cenário do curso de Engenharia Química (FRANKENBERG, 1998; FRANKENBERG, 1996, FRANKENBERG et al, 2001; FRANKENBERG e CARNEIRO, 1991, FRANKENBERG e CÔRTES, 2005 e GIUGLIANI et ali, 2004). Nestes trabalhos, observamos a importância do desenvolvimento cognitivo do aluno no sentido de gerar um pertencimento ao curso, bem como entender o curso que escolheu.

\subsection{Características da disciplina}

No semestre em estudo, foi oferecido duas turmas da disciplina de Introdução à Engenharia Química, em horários subsequentes. No modelo remoto foi possível unir facilmente as turmas para algumas atividades conjuntas.

Considerando as duas turmas teve-se $77,5 \%$ de alunos ingressantes via vestibular, $15 \%$ via PROUNI e 7,5\% alunos de transferência ou ingresso diplomado. Num total de 39 alunos observou-se que $27,7 \%$ eram mulheres e $73,3 \%$ homens, somente $16,6 \%$ estão trabalhando e $22,2 \%$ já realizaram ou estão realizando em paralelo outro curso superior. A média de idade dos calouros é de 18,4 anos. Os dados apresentados coincidem com os já apresentados por Frankenberg e Carneiro (1991 e 1995) e também por Silva (1989). 


\section{ESTUDO DE CASO - MUDANÇAS METODOLÓGICA}

Um dos maiores desafios no processo de Ensino Remoto, foi o de adaptar metodologias para o desenvolvimento de determinados conteúdos tratados na disciplina. Neste item iremos trazer alguns exemplos de como estas atividades foram desenvolvidas no primeiro semestre de 2020 fazendo um comparativo de como este processo ocorre no presencial.

\section{Visita aos laboratórios}

Ao longo do semestre, no processo presencial, visita-se os diferentes laboratórios específicos do curso, onde são apresentados a estrutura do laboratório, as pesquisas realizadas, as disciplinas que utilizam o espaço, e também é realizado algum experimento, cujo objetivo e aproximar o aluno da área ou áreas em que o laboratório atua. Procura-se, sempre que possível, ter vários experimentos funcionando visto que o horário das aulas dificilmente coincide com os bolsistas e pesquisadores que atuam no laboratório. Quando temos bolsistas, ou alunos de mestrado ou doutorado no momento da visita, estes são convidados a explicar e mostrar suas pesquisas.

Em relação as atividades remotas, tivemos vários desafios quanto a esta atividade. Primeiro, dentro de uma primeira expectativa, pretendia-se retornar as atividades presenciais antes do final do semestre, desta forma o programa da disciplina foi reorganizado deixando para as semanas finais as visitas aos laboratórios. Ao longo do mês de abril, observou-se que a pretensão de retorno ficava cada vez mais distante, e assim iniciou o questionamento: "como fazer as visitas de forma virtual, ou devemos suspender a disciplina até o retorno presencial?".

Neste contexto, a ideia inicial, foi o de gravar uma visita aos laboratórios. Para esta atividade, houve a necessidade da solicitação de acesso ao prédio da Escola (que segue um rigoroso sistema de controle e segurança sanitária). Tendo sido aprovada, gravamos a primeira visita, tendo como resultado um vídeo longo, com vários sons ambientes (locomoção, respiração, movimentos de materiais...), além de problemas de foco e muitos deslocamentos de imagem. Assim, foi necessário o aprendizado de algum software para edição deste vídeo.

Em relação a edição de vídeo, procuramos auxilio. Conversando com colegas sobre os procedimentos didáticos e ferramentas utilizadas, foi sugerido o software "Shotcut", por ser de fácil utilização e estar disponível de forma gratuita.

Quando se iniciou a edição do vídeo, foi observado que durante a visita virtual, os experimentos estavam estáticos, ou seja, era uma "passada" pelo laboratório. Com isto iniciamos a busca de experimentos semelhantes, ou o funcionamento de equipamentos disponíveis de forma pública no YouTube, assim foram incluídos nos vídeos das visitas vídeo onde poder-se-ia observar os experimentos realizados (Figura 1a, 1b, 1c e 1d). Além disto, com a visualização dos experimentos, foram disponibilizados dados decorrentes de alguma prática, e os alunos tiveram a oportunidade de realizar a interpretação destes dados. Quanto as pesquisas, nos laboratórios se tem o costume de deixar publicado nas paredes os trabalhos que foram apresentados na forma de pôster. Assim, as pesquisas foram apresentadas e discutidas com os alunos (Figura 1d).

A experiência gerou uma gama de novas atividades e. consequentemente, um aprendizado em edição de vídeos, bem como na organização e gerenciamento destes vídeos. Durante as aulas, os vídeos foram apresentados com narração síncrona, onde se pode parar e explicar pontos importantes dos laboratórios, permitindo assim a interação dos estudantes no sentido do entendimento e sanado dúvidas. 
Figura 1 - Imagens do vídeo referente a um dos

laboratórios onde (a) entrada do laboratório, (b) um dos

laboratórios de análise, (c) equipamento (reator) e (d) pôster de trabalhos dos bolsistas.

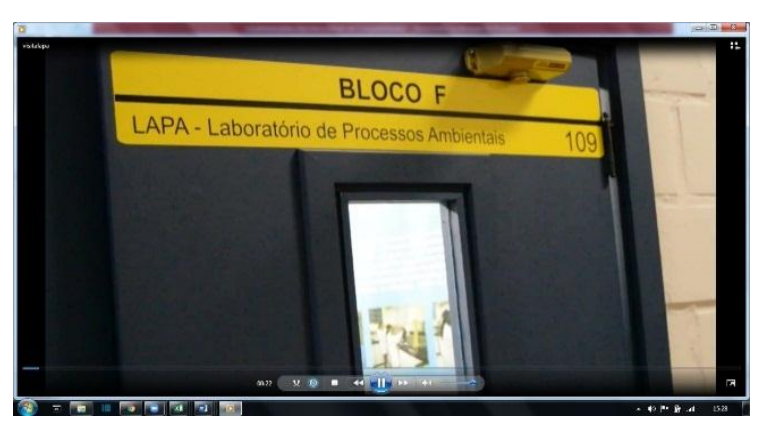

(a)

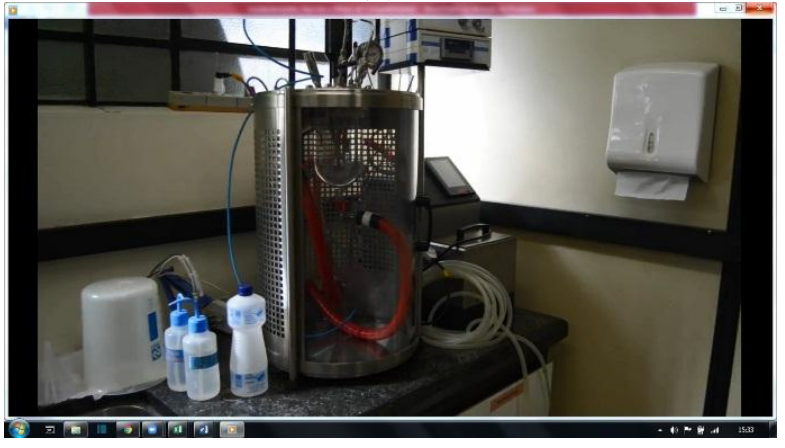

(c)

Fonte: Autor

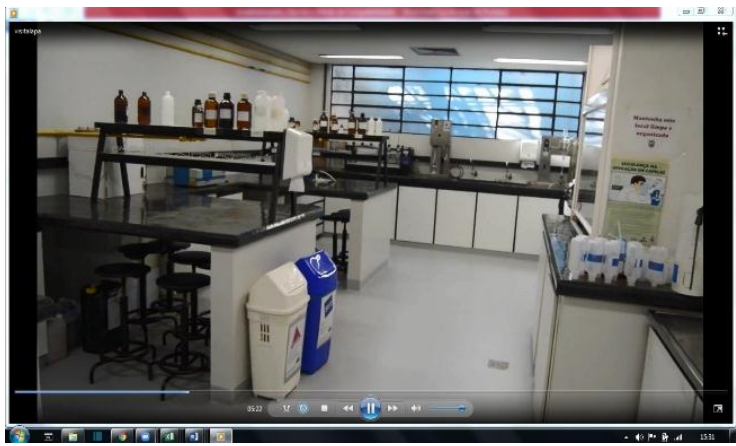

(b)

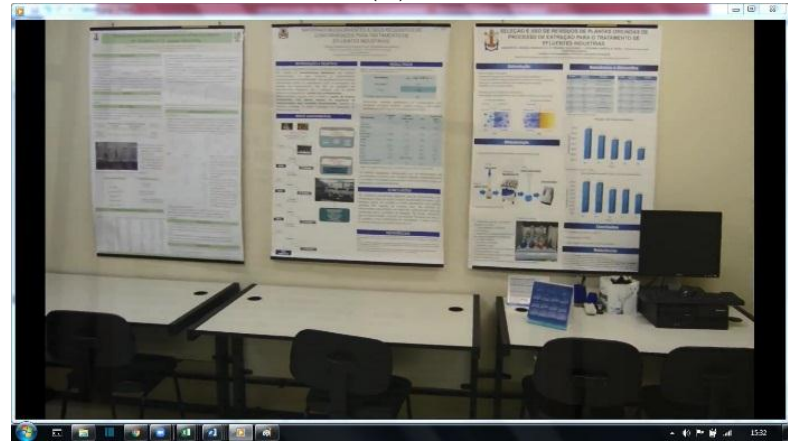

(d)

\section{Avaliação de disciplinas}

No modelo presencial num determinado momento do curso são discutidos os processos de avaliação (de disciplina, de curso e institucional). Para isto, apresentamos todos os conceitos de avaliação, passando pelo ENADE, o que significa CPC (Conceito Preliminar de Curso), IGC (Índice Geral de Cursos Avaliados da Instituição) e assim por diante, mostrando a estrutura do INEP/SINAES quanto as avaliações bem como as avaliações de disciplinas (a Universidade utiliza dois momentos de avaliação uma Intermediária e uma Final).

Lembramos que a proposta do SINAES (Sistema Nacional de Avaliação da Educação Superior), conforme Polidori (2009), "compreende a necessidade das IES passarem por um ciclo completo de avaliação". Desta forma, esse ciclo envolve basicamente três pilares deste Sistema: avaliação institucional, avaliação de cursos e avaliação de desempenho dos estudantes. Obviamente este processo não pode ser considerado como sendo uma dinâmica linear, pois cada um dos pilares indicados, compreendem vários estágios e atuações que se diferem de IES para IES. Aliás, este é um dos grandes princípios do SINAES: "respeitar as diferenças e as especificidades de cada IES" (BRASIL, 1996).

Do ponto de vista metodológico, iniciamos a aula com um desafio, onde todos os alunos recebem uma imagem e é cronometrado um tempo em que o aluno deve responder um questionamento sobre esta imagem. Recolhe-se as imagens e se revela os resultados, que sempre são bastante contraditórios, e com isto questiona-se o estudante do porquê destas diferenças, visto que todos viram a mesma imagem no mesmo tempo? Assim inicia-se a discussão do objetivo da atividade, ou seja, todos viram a mesma coisa, no mesmo tempo, porém cada um tem na sua formação pessoal e acadêmica diferente, um histórico diferente e 
principalmente uma percepção diferente sobre alguma coisa. Neste momento se introduz o que acontece em uma avaliação de disciplina, todos estão na mesma sala, mas nem todos vêm aquela disciplina da mesma forma, e por isto a importância do processo avaliativo das disciplinas.

Em um segundo momento, após a discussão sobre o que será tratado (avaliação de disciplinas) são discutidos/levantados pontos importantes neste processo de avaliação, e por mais que as turmas sejam diferentes sempre temos como primeiro item citado pelos alunos que o que eles observam quando avaliam uma disciplina é "o professor" e consequente mente por último, depois de muito direcioná-los "o eu". Nesta discussão vai se estruturando a importância de cada critério que devem ser avaliados: professor, conteúdo, didática, metodologia, horário da disciplina, turma, infraestrutura, material disponibilizado e provas e trabalhos.

Para dar fechamento a aula, os alunos são convidados a avaliar as disciplinas do semestre, onde eles preenchem quatro itens para cada disciplina: como eles estão na disciplina (bem, péssimos, regulares...); quais os pontos positivos; quais os pontos negativos e quais soluções que ele imagina de como resolver os pontos colocados como negativos. Lembrando que todos os dados devêm ser baseados no que foi discutido anteriormente.

No processo remoto, as etapas desta atividade foram realizadas basicamente da mesma forma, só que utilizando as ferramentas disponíveis. Na Universidade, foram propostas duas plataformas oficiais para auxiliar no processo de Ensino Remoto. O ambiente Moodle que já é a plataforma oficial da Universidade e o uso da ferramenta de videoconferência (Zoom), sendo indicado o uso do YouTube através da criação de um canal ou OneDrive para armazenamento de vídeos e documentos (assim não sobrecarregando o Moodle).

Na primeira etapa da aula foi disponibilizada uma imagem no Zoom (Figura 2a) durante 1 minuto, neste período os alunos tinham que colocar no chat o número de quadrados que eles conseguiram identificar (este foi o desafio proposto). Após este momento observamos as respostas e consequentemente discutimos o porquê das diferenças entre as respostas da mesma maneira que no processo presencial. Já no segundo momento foi apresentado aos alunos um histórico sobre avaliação (CPC, SINAES, INEP, ENADE...). Posteriormente, a esta apresentação, foi realizado a elaboração de critérios de avaliação de forma conjunta utilizando o whiteboard do Zoom (Figura 2b), com isto foram construídos os pontos a serem avaliados em uma disciplina. E para fechamento, o levantamento dos itens que se faz também no presencial foi colocado aos alunos na forma de uma Tarefa, onde eles tinham que preencher um formulário para cada disciplina que ele estava cursando com exceção da turma de Introdução (avaliação é realizada posteriormente). Junto aos formulários foram disponibilizados os itens discutidos na segunda etapa da aula. Os formulários foram elaborados utilizando o Microsoft Forms como mostrado na Figura 2c.

\section{Bate-papo com ex-alunos}

Um ponto interessante ao longo do semestre é a visita de ex-alunos do curso em uma determinada aula onde estes convidados a conversar com os calouros. Neste bate-papo os exalunos falam do seu histórico, onde estão atuando, sua trajetória, pontos importantes ao longo do curso, o que foi importante no curso e/ou Universidade.

No modelo presencial existem problemas em função das disponibilidades do convidado estar presente em um determinado horário e na Universidade. Neste sentido, a grande maioria dos convidados, são engenheiros recém-formados, por estarem ainda com uma rotina próxima a Universidade. Normalmente os convidados possuem características diferenciadas profissionalmente (realizando mestrado, trabalhando em indústria, trabalhando em pesquisa...). 
Figura 2 - Imagens de várias etapas da atividade referente a avalição de disciplinas onde (a) desafio proposto aos alunos, (b) whiteboard para discussão sobre os itens a serem avaliados e (d) exemplo da etapa de avaliação das disciplinas no Microsoft Forms.

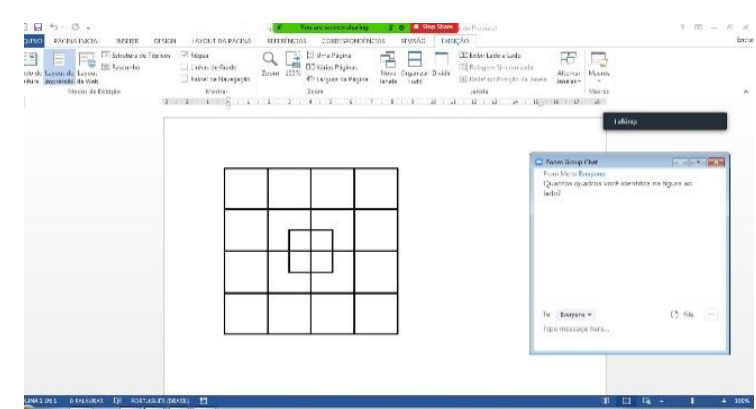

(a)

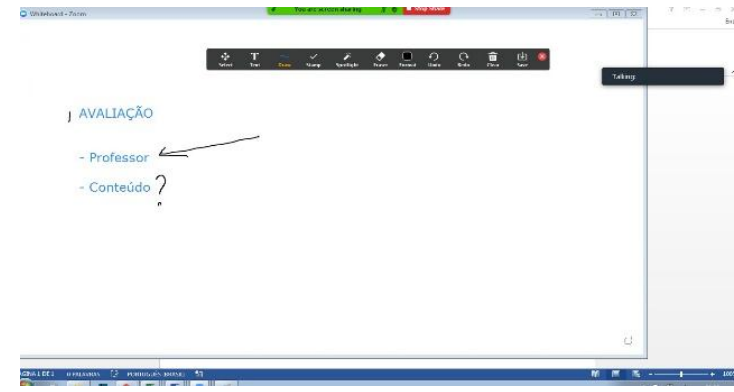

(b)

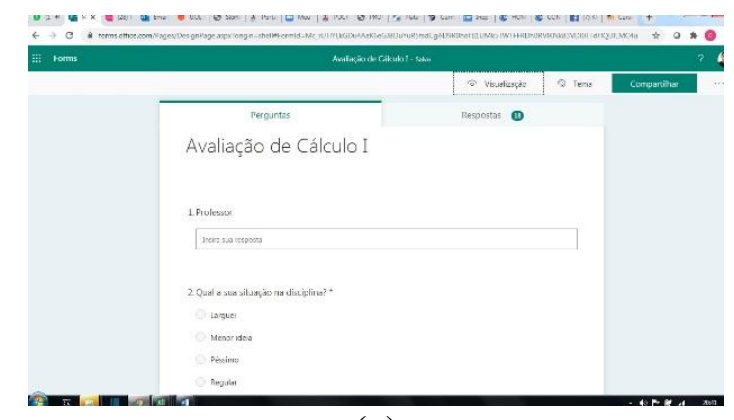

(c)

Fonte: Autor

A situação atual (Modelo de Ensino Remoto), trouxe uma facilidade para se organizar esta atividade. Foi possível convidar profissionais que atuam em diferentes locais do país, bem como características profissionais distintas, que em situações normais seria impossível reuni-los. Com esta vantagem, pode-se, neste semestre, realizar a reunião com um ex-aluno que está no mercado a mais de vinte anos, um intermediário trabalhando com pesquisa, e um recémformado. Buscamos profissionais com experiência de mobilidade durante a firmação ou durante a sua careira profissional. A Figura 3 mostra a reunião que foi conduzida no Zoom, onde além dos alunos da turma também foram convidados os alunos de outras disciplinas, que no modelo presencial ficaria mais difícil de ocorrer devido basicamente a horários das disciplinas.

A Figura 3 mostra um momento do bate-papo que ocorreu no primeiro semestre de 2020, imagem esta retirada do YouTube onde todos os encontros síncronos ficam gravados.

\section{LIÇÕES APRENDIDAS}

As lições apreendidas com as novas metodologias empregadas foram bastante significativas. A forma de observar estas lições foi através da avaliação da disciplina (MOREIRA; MAINIER e PASSOS, 2006). No último encontro da disciplina foi solicitada uma tarefa, onde os alunos receberam um instrumento de avaliação onde foram avaliados vários pontos: auto avaliação, dados discutidos ao longo do semestre, avaliação da disciplina e retomadas questões que foram disponibilizadas para os estudantes no primeiro dia de aula.

Em relação a autoavalição os alunos são desafiados a concederem uma nota para e uma justificativa para esta nota, no que tange a disciplina e também em relação ao semestre. Um 
estudo sobre este procedimento foi desenvolvido por Frankenberg e Côrtes (2005), Bazzo; Pereira e Linsingen (2000) e Bittencourt (2011).

Figura 3 - Imagens do bate-papo com ex-alunos.

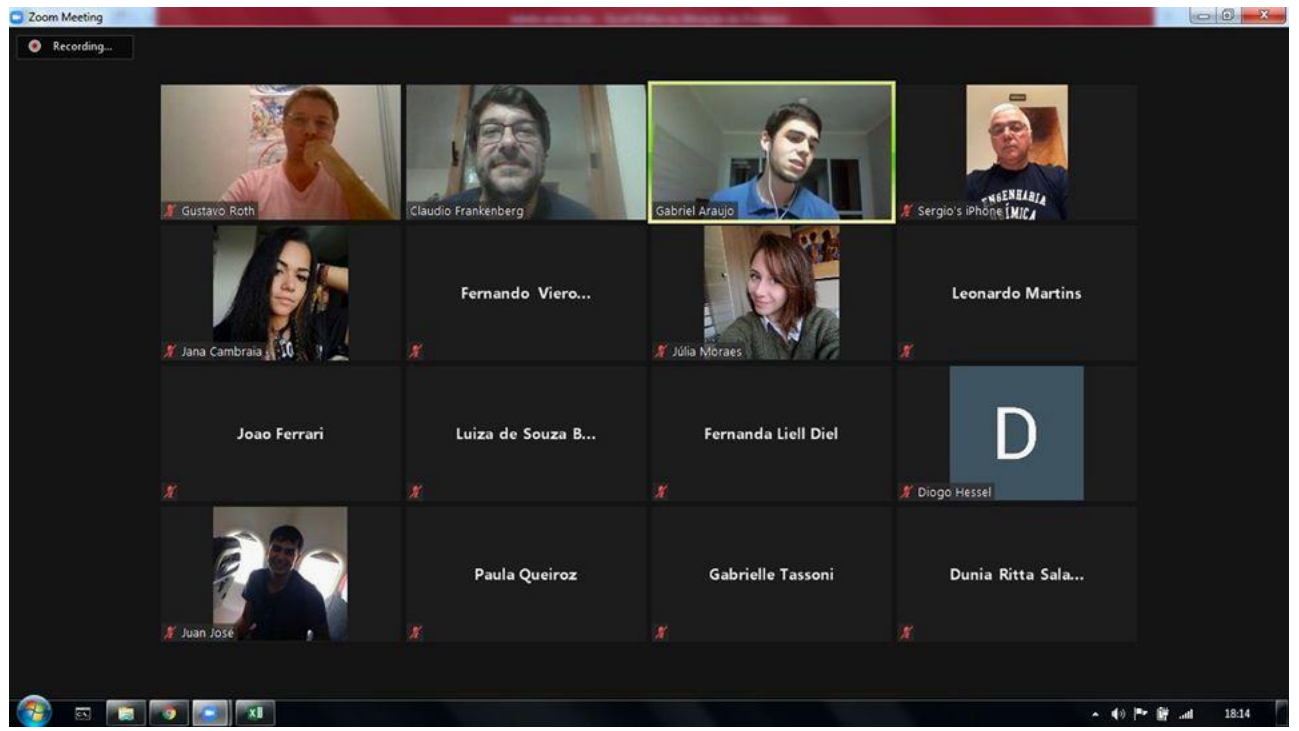

Fonte: Autor

No que diz respeito a repetição das questões propostas no primeiro dia de aula, o objetivo é verificar as mudanças sobre as percepções do que é Engenharia química, o que o engenheiro químico faz e onde ele atua. Já no que tange os dados discutidos no semestre foram colocados de forma a verificar-se os diferentes pontos discutidos ao longo do semestre.

Quanto a avaliação da disciplina, foco deste item, os alunos foram questionados sobre os seguintes tópicos: (1). Para você a disciplina de Introdução à Engenharia Química atendeu os objetivos esperados (localizar o aluno no curso, dar uma visão do profissional, orientar quanto aos procedimentos didáticos e acadêmicos, explicar o currículo, entre outros)? (2) O que você acha que deveria ser tratado na disciplina além dos pontos discutidos durante o semestre? (3) Relacione os pontos positivos e negativos que você observou na disciplina de Introdução à Engenharia Química? (4). Qual a importância que você vê nesta disciplina, dentro do currículo de Engenharia Química?

Segundo Creutzberg, et al (2018), o que corrobora com o instrumento utilizado, a avaliação educacional e a avaliação de disciplinas geram polêmicas no âmbito da educação superior, a começar pelos instrumentos utilizados, assim adicionalmente, sustenta-se que a avaliação de disciplinas não seja vista como um processo desconectado do planejamento da disciplina, com base em uma perspectiva de avaliação formativa, orientada à promoção da aprendizagem dos estudantes.

Organizando-se os dados descritos pelos estudantes no item (3), foram elaboradas duas as duas nuvens de palavras conforme mostrado nas Figuras 4 e 5 (pontos positivos e negativos respectivamente).

Observa-se que na Figura 5, os principais pontos levantados foram a respeito do papel do professor, já na Figura 5 as necessidades de infraestrutura (laboratórios, espaços de convivência), bem como visitas a atividades presenciais foram as características salientadas como pontos negativos, no sentido de não terem ocorrido no processo Remoto, na forma que os estudantes esperavam, ou tinham expectativa. 


\section{COBENGE COBBNGE 2020 da ABENGE}

Figuras 4: Nuvem de palavras sobre os pontos positivos relatados pelos alunos.

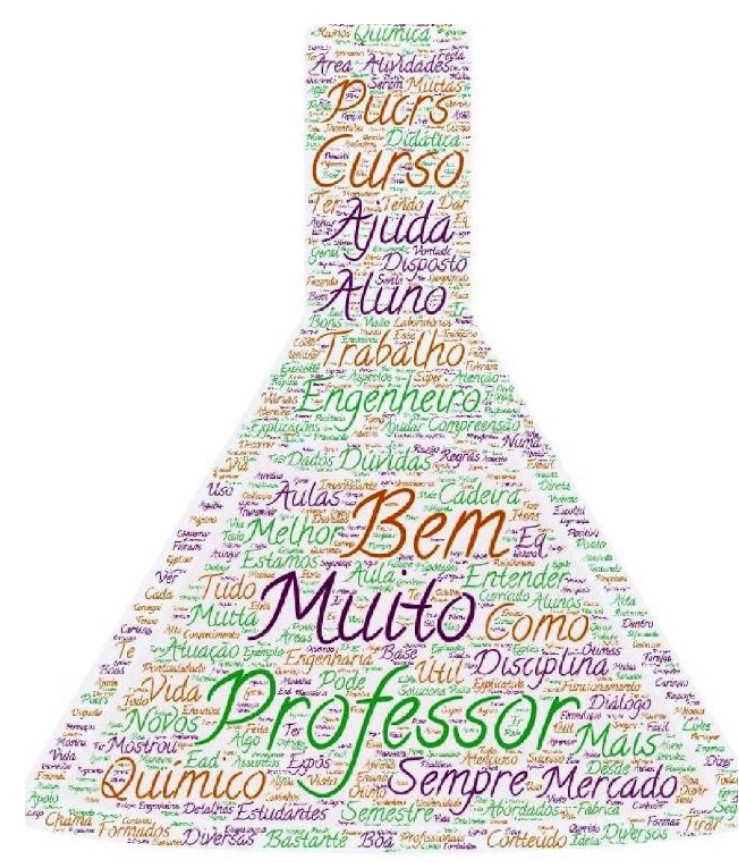

Fonte: Autor
Figuras 5: Nuvem de palavras sobre os pontos negativos relatados pelos alunos.

\section{CONSIDERAÇÕES FINAIS}

A Universidade disponibilizou através do seu setor PUCRS Online uma série de tutorias para auxiliar no desenvolvimento das atividades remotas, bem como o Núcleo Inovação Pedagógica (NIP) da Escola auxiliou de foram constantes os professores. O grande desafio em relação a uma disciplina de primeiro nível, foi a de motivar os estudantes, e de fortalecer o pertencimento ao curso escolhido. Neste contexto, conforme foi comentado em alguns exemplos relatados neste trabalho, a disciplina de Introdução à Engenharia Química conseguiu atingir de forma adequada os seus pressupostos.

Os calouros, apesar de não terem tido a oportunidade de atividades hands-on, conseguiram conhecer o curso, a Escola e a Universidade, como através do acolhimento realizado se sentiram pertencentes a esta nova comunidade. Em suma, conforme relatado por Rodrigues (2020) o desafio do Ensino Remoto propicia, se bem adequados e aplicados conquistas positivas.

\section{REFERÊNCIAS}

BAZZO, W. A.; PEREIRA, L. T. V.; LINSINGEN, I. V. Educação Tecnológica. Florianópolis: Editora da UFSC, 2000.

BITTENCOURT, H. R., CREUTZBERG, M., RODRIGUES, A. C. M., CASARTELLI, A. O., \& FREITAS, A. L. S. (2011). Desenvolvimento e validação de um instrumento para avaliação de disciplinas na educação superior. Estudos em Avaliação Educacional, 22(48), 91-114. 
BRASIL. Lei no. 10.861, de 14 de abril de 2004. Institui o Sistema Nacional de Avaliação da Educação Superior - SINAES. Diário Oficial [da] República Federativa do Brasil, Brasília, DF, 20 mar 1996. Seção 1, p. 4686.

BRASIL. Ministério da Educação. Portaria n 343, de 17 de março de 2020. Dispõe sobre a substituição das aulas presenciais por aulas em meios digitais enquanto durar a situação de pandemia do Novo Coronavírus - COVID-19. Diário Oficial da União, Brasília, DF, 18 mar. 2020. p. 39. Disponível em: http://www.in.gov.br/en/web/dou/-/portaria-n-343-de-17-demarco-de-2020-248564376. Acesso em: 27 mar. 2020.

CREUTZBERG, M., DILIGENTI, M., BENEDETTO, I., BITTENCOURT, H., CASARTELLI, A., MELO, D., \& DIAS, M. Avaliação Institucional: Acolhimento E Contraponto À Evasão Na Educação Superior. Congresos CLABES. Recuperado a partir de https://revistas.utp.ac.pa/index.php/clabes/article/view/2042, 2018.

FRANKENBERG, C. L. C.; CARNEIRO, M. L. F. Evasão no Curso de Engenharia Química da PUCRS: Quando e Porque? In: XXIII Congresso Brasileiro de Ensino de Engenharia, 1995 XXIII COBENGE., 1995. p.1219 - 1228.

FRANKENBERG, Claudio L. C. Caracterização das Atividades Preferenciais dos Alunos Ingressantes no Curso de Engenharia Química da PUCRS. In: Anais do COBENGE98, ABENGE. São Paulo: COBENGE98, 1998, vol. 1. p.462-475.

FRANKENBERG, Claudio L. C. e CÔRTES, Helena S. O uso da autoavaliação como uma ferramenta de avaliação nos cursos de engenharia: estudo de caso da Engenharia Química da PUCRS. In: XXXIII CONGRESSO BRASILEIRO DE ENSINO DE ENGENHARIA, Campina Grande. Anais do XXXIII COBENGE. 2005

FRANKENBERG, Claudio L. C. Implementação da Disciplina de Introdução à Engenharia na PUCRS: Diagnóstico nos Cursos de Engenharia. In: XXIV Congresso Brasileiro de Ensino de Engenharia, 1996, XXIV COBENGE. Manaus: Imprensa Universitária, 1996. v. 02. p.195-212.

FRANKENBERG, Claudio L. C.; BRUN, Gerti W.; VARGAS, Rubem M. F.; CASSEL, Eduardo; CANTELLI, Marlize e BAUER, Paulo E. Reestruturação Curricular do Curso de Engenharia Química da PUCRS: Proposta e Metodologia. In: XXIX Congresso Brasileiro de Ensino de Engenharia, 2001, Experiências Concretas no Ensino de Engenharia - XXIX COBENGE. Porto Alegre: CD+, 2001. v. NTM. p. 299 - 305.

FRANKENBERG, Claudio L.C. e CARNEIRO, Mara L.F. Avaliação do Perfil do Estudante de Engenharia Química da PUCRS. Anais do IV Encontro Brasileiro Sobre o Ensino da Engenharia Química, Associação Brasileira de Engenharia Química, Itatiaia, 1991, pp.138-157.

GIUGLIANI, Eduardo; GUEDES, Luis F. M.; FRANKENBERG, Claudio L. C; VESCOVI FILHO, Virgílio. Introdução à Engenharia: Uma Proposta de Gestão Integrada para Diversos Cursos - Faculdade de Engenharia - PUCRS In: XXXII Congresso Brasileiro de Ensino de Engenharia, 2004, Brasília - DF. COBENGE 2004 
MOREIRA DA SILVA, R. R. C.; MAINIER, F. B.; PASSOS, F. B. A Contribuição da Disciplina de Introdução à Engenharia Química no Diagnóstico da Evasão. Ensaio: Avaliação de Políticas Públicas Educacionais. Rio de Janeiro, v.14, n.51, p. 261-277, abr./jun. 2006.

PIMENTEL, Mariano. \#FiqueEmCasa, mas se mantenha ensinando-aprendendo: algumas questões educacionais em tempos de pandemia. Revista Horizontes - SBC, março de 2020. Disponível em http://horizontes.sbc.org.br/index.php/2020/03/30/fiqueemcasa/. Acesso em: 16 jul. 2020.

POLIDORI, Marlis Morosini. Políticas de avaliação da educação superior brasileira: Provão, SINAES, IDD, CPC, IGC e. outros índices. Avaliação (Campinas), Sorocaba, v. 14, n. 2, p. 439-452, July 2009 Disponível em <http://www.scielo.br/scielo.php?script=sci_arttext\& pid=S1414- 40772009000200009\&lng=en\&nrm=iso > . Acesso em: 04 Aug. 2020.

RODRIGUES, Alessandra. Ensino remoto na Educação Superior: desafios e conquistas em tempos de pandemia. Revista Horizontes - SBC, julho de 2020. Disponível em http://horizontes.sbc.org.br/index.php/2020/06/17/ensino-remoto-na-educacao-superior/.

Acesso em: 16 Jul. 2020.

SILVA,. J. R. G. Perfil de Alunos Recém-Ingressos no Curso de Graduação em Engenharia de Materiais da UFSCar. In: Anais do COBENGE 89. ABENGE. Curitiba: COBENGE89, 1989, pp.427-440.

\title{
REPORT AND EXPERIENCE OF REMOTE EDUCATION IN A FIRST SEMESTER DISCIPLINE IN THE CHEMICAL ENGINEERING COURSE AT PUCRS
}

\begin{abstract}
This work presents a state of the art on transferring the face-to-face model to the remote model in a first level discipline of the Chemical Engineering course, based on a comparative description of the two models in different activities. In general, the implementation and operation of Remote Synchronous Teaching is evidenced to carry out academic training activities in a discipline whose main objective is the students' sense of belonging to the course and the University. With this, this study addresses the insertion of remote experimentation in teaching practice in higher engineering courses in order to understand the pedagogical complexities of this type of methodology. The remote model used worked with platforms such as Moodle and Zoom. Through this, the academics showed a good receptivity at the end of the course and felt safe in relation to the process we faced this semester (2010/1). In short, the remote process, in general, was seen as a positive resource in the teaching and learning process for students in higher education in chemical engineering, however, some points showed a need for improvement.
\end{abstract}

Keywords: Remote Education. Coronavirus. Freshmen students. 